\title{
Filtered tailings adds value in cost competitive industries
}

\author{
Richard Williams McLanahan Corporation Pty Ltd, Australia \\ Dennis Zink McLanahan Corporation, USA \\ Scott O’Brien McLanahan Corporation, USA
}

\section{Abstract}

There is an industry perception that filtered tailings can be a costly process that many operations may find difficult to sustain. While undoubtedly adding equipment to any process raises cost concerns, case histories are presented of several small scale operations in the USA and other global locations that have justified these costs, and proceeded to install and operate filtered tailings. Typically the major driver for investment is the elimination of wet tailings storage allowing a smaller footprint, reduced operating cost and access to water in addition to compliance with ever more stringent local environmental obligations.

\section{Introduction}

While the United States has seen a decline in domestic large scale minerals mines, it is estimated that over 2.1 billion tons of aggregates and industrial sands (glass sand, hydraulic fracturing sand, etc.) are processed and washed each year. In these industries, the value of the product can range in the USD 10 to 80 per ton mark with the bulk being on the lower end of that scale. Many of these plants are located near urban areas where land and water is more expensive, good neighbor policies abound, and frugal management of their reserves are required to gain full benefit from their mining endeavor. For this industry, gaining the permit to mine, expand a mine, change a process or as is applicable to the studies presented here, apply for installations of tailings ponds is an arduous process. With regard to the latter, tailings ponds are becoming extremely difficult to have permitted.

Coal in the U.S. has admittedly taken an economic beating recently yet there are still a number of producers and key to their continued success is in better tailings management both from regulatory and public perception standpoint.

Up until about 30 years ago these industries relied on settling ponds for storage of tailings and water recovery. With increases in regulation, costs of permitting, and more stringent environmental regulations, it was soon realized the actual costs involved with maintaining ponds, tying up reserves and replenishing water losses to evaporation and leaks was not as economical as this solution may have once been. The first advance into modern tailings management was to consider conventional or high rate thickeners as the ultimate solution to their woes. While this provided a method for immediate return of water for process use the thickener alone still required a tailings pond to store silts and fines.

Around 2010 several locations began looking for a more cost-effective way to manage their tailings. They were individually driven by a variety of issues including, further reduction of space for tailings storage, costs to rehabilitate or manage tailings areas, or local government regulations around wet storage. 
A significant shift in public opinion on the management of waste facilities and the ability and intent to repurpose tailings materials (Van Zyl et al., 2017) has changed the economic driving force for many projects. Examples are noted in this Paper where this has been achieved.

While a filtered tailings solution is a commonly recognized technical solution there is a perception within this industry that the costs of such an endeavor are prohibitive. By working with each site on a customized basis it has been possible to deliver a bespoke plant that enhances the opportunity of each plant to extract additional value to defer costs and/or provide cost-competitive designs. Highlighted in this paper are a number of case histories, each subtly different, yet all providing a similar filtered tailings outcome.

\section{Evaluation}

\section{$2.1 \quad$ Testwork}

Tailings can be described as the residue left after extraction or processing of a mineral deposit. However separate industries may ascribe differing terms to this material. For example the coal industry particularly in the US may describe this as "refuse". They are characterized by the unique lithology of the parent deposit and the method of processing the ore has been subject to. Therefore unless extracted from the same deposit and processed by the exact same method no two tailings samples will behave in the same manner. To permit an optimal plant design and to provide the customer with some certainty over process outcomes it is essential test work on samples be undertaken. Some care should be exercised about endeavoring to ensure samples are representative of the proposed feed to the tailings plant.

A typical test work program may consist of the following:

- Sample characterization including.

- Particle Size Distribution.

- Solids Concentration of the "as received" sample.

- Solids specific gravity.

- $\quad \mathrm{pH}$ of the as received sample.

- Chemical Screening to define a suitable reagent and dose for further test work.

- Sedimentation testing including.

- Static Thickener test with pickets to generate a Kynch (Kynch, 1952) curve and produce a sludge suitable for viscosity test work.

- Dynamic Thickener testing to determine appropriate maximum hydraulic loading.

- Pressure Filtration Testing including.

- evaluation of cake thickness.

- pressure required.

- resultant cake moisture.

- cycle time.

Membrane and cake blow testing may also be investigated to check the efficacy of these as they relate to the sample.

\subsection{Equipment selection}

Equipment selection and the Process Flow Diagram can only be undertaken once results of the test work program are known and a mass balance is agreed with the site. This can consist of various combinations of the equipment but primarily pumps, hydrocyclones, dewatering screens, thickeners, filters, reagent dosing systems, tanks and agitators. These can be broken down into three key unit operations as discussed below. 


\subsubsection{Ultra fines recovery (UFR)}

The UFR consists of a sump, pump, cyclones and dewatering screen. In a sand or gravel plant the inclusion of a UFR can frequently recover down to the 38 micron and fraction that might otherwise be sent to tailings for recovery to valuable product. The material that is recovered exits the dewatering screen in a state that may be conveyed and stockpiled. The mantra for many plant operations is that if you can stack the material, someone will find a use for it. Indeed these fines, while not on their own suitable for concrete or mason sands, can often be used to blend back with these primary sands to a point. On their own, they are often sold as pipe bedding, soil amendment, or pool sand. Sales creativity has even lead to some higher priced sands such as "Optical Fiber Bedding Sand". For one operator in 2004, this particular sand went from a waste to one that commanded USD 14 per ton.
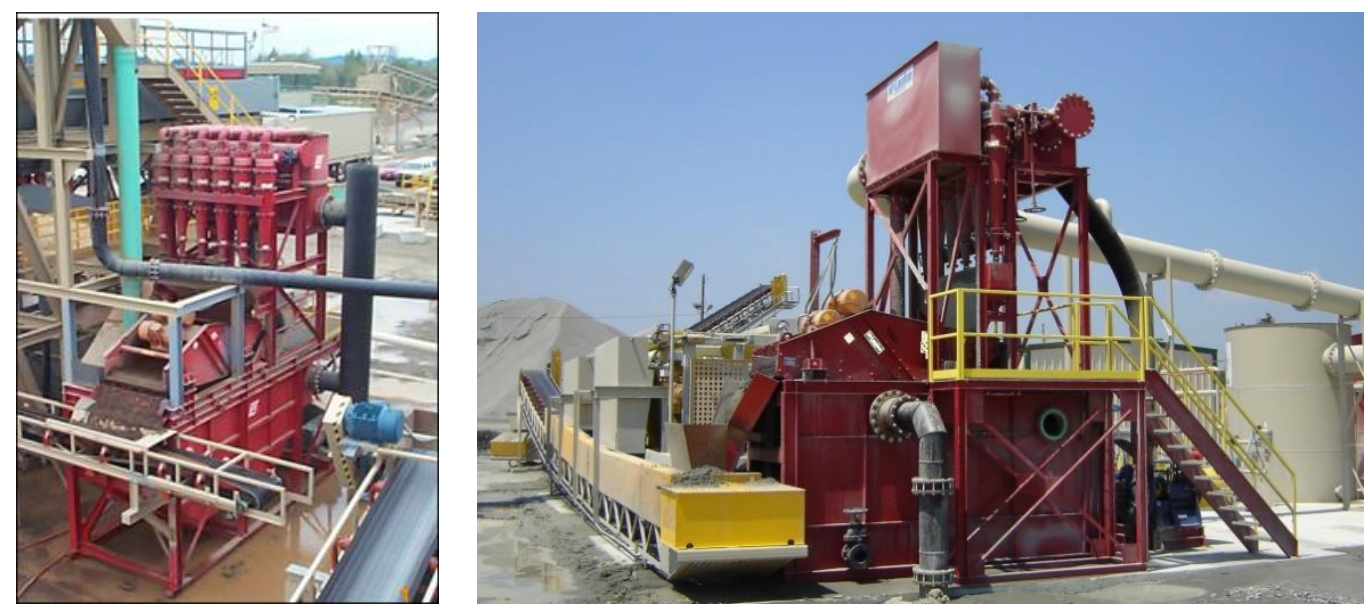

Figure 1 Typical UFR modules including multiple smaller diameter cyclones and dewatering screen

\subsubsection{Thickener}

A variety of thickener types have been used subject to overflow clarity and underflow density requirements. Generally these can range from high rate thickeners through high density thickeners to paste thickeners. Tankage can be either elevated or on-ground and tanks can be constructed from bolted or welded sections. Almost all thickener selections combine the use of synthetic polymers to aid settling and reduce equipment size (Fawell et al., 2009).

\subsubsection{Filter}

The target moisture content and subsequent driving force required will influence the filter type. The target moisture in turn needs to be identified on the basis of the proposed emplacement, transport and residue storage area. The mineralogical composition and particle size distribution and the expected variation in both can be critical to achieving the target moisture. This process depending on location and size may be the subject of extensive geotechnical and economic evaluation (Arash et al., 2016).

\subsubsection{Flowsheet}

For all applications assessed, the following generic flowsheet shown in Figure 2 has been applied although as discussed above and in case histories below detailed equipment designs are different.

For sand, gravel and coal tailings the particle size distribution typically contains $80 \%$ less than $45 \mu \mathrm{m}$. At this size distribution it has been found a minimum driving force of $6 \sim 15$ bar is required to produce a formed cake with moisture content of $20 \sim 30 \%$ by mass. The most cost effective equipment to achieve this is a recessed chamber filter press. 


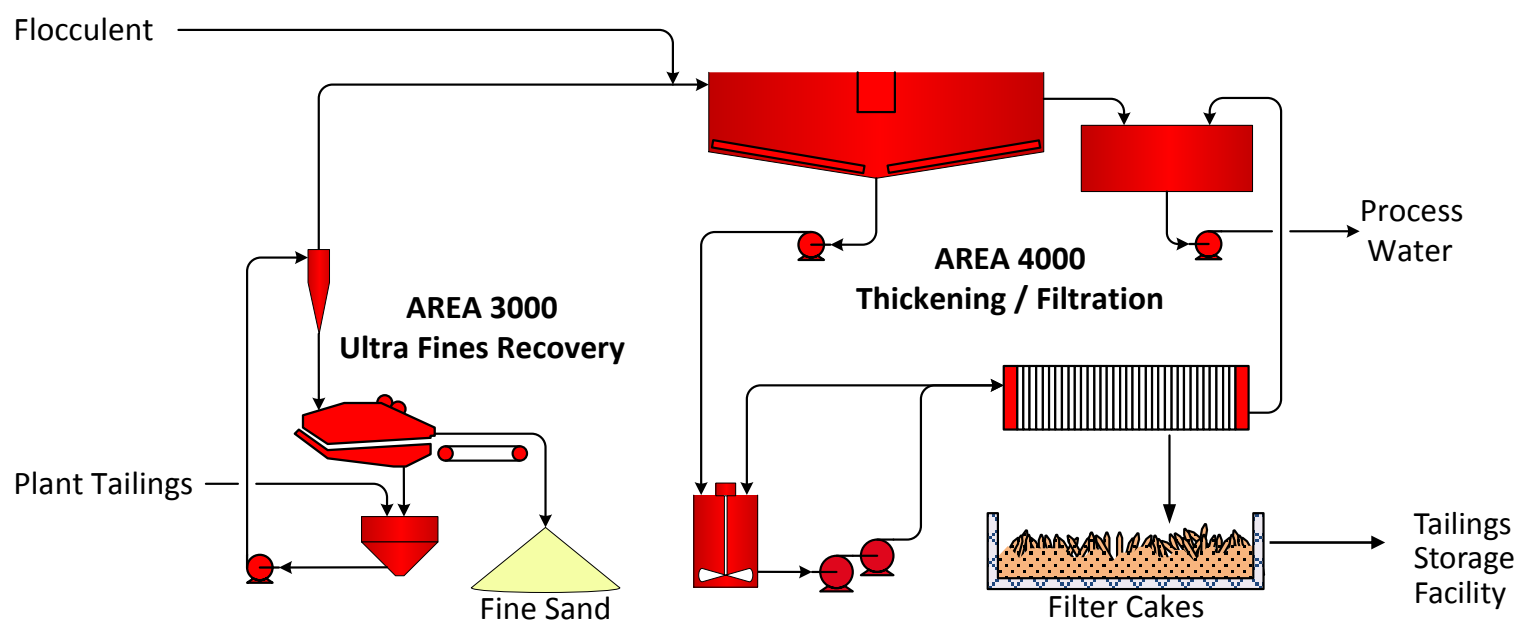

Figure 2 Generic plant fines recovery and filtered tails flowsheet

\section{$3 \quad$ Case studies}

\subsection{Site A, Central California, USA}

This plant is located in a steep canyon near an urban area with little opportunity for increasing the storage area. The owner was frustrated by the lost time, high costs and mounting inconveniences associated with the settling pond (Voss, 2013). Due to the size of the pond and the nature of the tails, both a coagulant and an anionic flocculent had to be mixed into the tailings to allow settling. Once the tailings accumulated in the pond, the plant had to be shut down for the pond to be cleaned out and made operational again. Furthermore, before disposal at the reclamation area was possible, the mucked out tails had to be blended with cement to increase the compaction necessary. A larger or additional pond would have helped matters but two realities loomed: the 170-acre operation had limited space for creating a second settling pond that would allow work to continue uninterrupted, and the permitting process for the additional pond would have been arduous.

Another issue for the owners was the very real opportunity to increase sales thanks to a strong economic environment. Giving up real estate and tying up reserves for a new larger pond would be a poor investment. Overall, it just didn't make sense to prolong dealing with ponds.

An Ultra Fines Recovery (UFR) system has made it cost-effective to recover nominal -100 x 38 micron fines as a conveyable, stackable fine sand product. It recovers more than $20 \mathrm{t} / \mathrm{hr}$ of the fine sand. When blended with clean fill from local excavations, the resulting material qualifies as a loamy soil and is sold to the landscaping centers servicing the San Jose area. At $500 \mathrm{~m}^{3} / \mathrm{hr}$, the overflow from this system contains predominantly fine chlorite clays with a P50 of 10 microns.

To deal with the UFR cyclone overflow, a paste thickener was selected over a traditional High-Rate thickener as the higher-density underflow was demonstrated in the lab to allow shorter filter press cycles and hence, lower total capital cost. The typical underflow solids concentration from the $8 \mathrm{~m}$ diameter thickener is 48 to $52 \%$ solids by weight with a yield stress of $100 \sim 150 \mathrm{~Pa}$.

A single $2 \times 2 \mathrm{~m} 180$ plate filter press located over a concrete bunker operates fully automatically discharging cakes every forty minutes. This press, originally installed with the goal to eliminate the tailings pond and produce material suitable for reclamation in the quarry, has also since become integral in a new source of revenue. Central California towns, concerned with flood abatement, had begun reconstructing levies. The 
filtered cakes were recognized as an ideal material to promote impermeability. Sold as "washed levy fill", this material commands a price that exceeds the quarry's base rock and sales are expected to be above 250,000 tons in 2017.

Finally, the original pond area was filled in and covered with a concrete pad. Conversion of this area to stockpile storage area essentially triples inventory. In addition, the pond elimination paved the way for improved truck traffic flow, shortening cycle times and improving safety.

The entire plant was delivered for a Capex of USD \$3.1 million.

As a result of the new system savings of nearly $\$ 1$ million a year associated with better tailings management (not having to "muck-out" tailings ponds) have been realized. In addition, they have gained an additional $50 \sim 75$ days each year of production where the entire operation was previously shut down. Notwithstanding the added revenue from tailings sales, savings from the elimination of the pond and investment in filtered tails totals an estimated USD 1.12 per net ton.
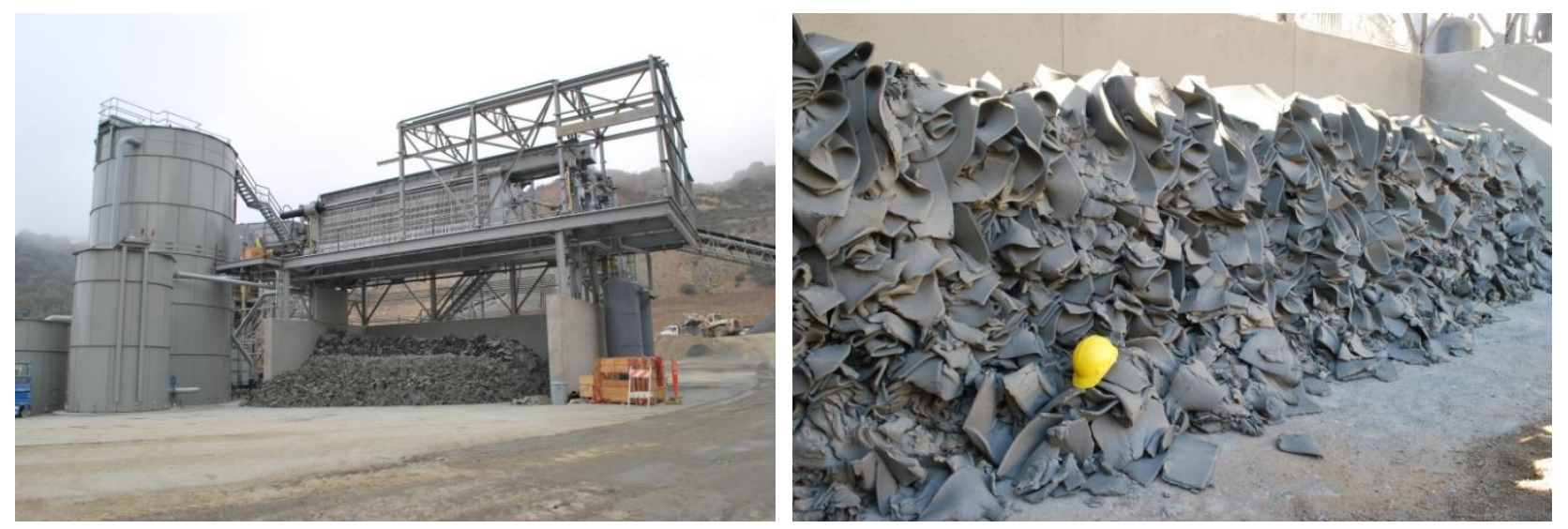

Figure $38 \mathrm{~m}$ paste thickener and $2 \times 2 \mathrm{~m}$ recessed plate press (Left) and “Washed Levy Fill” (Right)

\subsection{Site B, Wisconsin, USA}

Production of Hydraulic Fracturing Sand (frac sand) has brought to the agrarian economy something that is relatively new to the population in rural Wisconsin. Public concern regarding the development of frac sand deposits has resulted in most properties being particularly scrutinized for their tailings management plans. Tailings generated from the frac sand production are commonly filtered due to this, as the filtered tailings solution is perceived as having less impact on the environment.

Transport of tailings over public roadways for disposal in mined out areas requires that the tails be stabilized to a point where the probability of leaks and spills are nil. One central processing facility had incorporated belt filter presses to produce a tailings sludge that met this requirement as well as a minimum yield stress for placement. Unfortunately, the product from the belt presses did not meet the standards required and to manage this, the owners had to treat the waste prior to transport with a polymer to absorb excess water at a cost of hundreds of thousands of dollars per month. Clearly they need a more reliable solution so recessed plate presses were evaluated and chosen to upgrade the tailings facility. These cakes now comply with the disposal permit and regulations for transport. A smaller footprint of the tailing deposit is also realized enhancing the social acceptance of a new industry to the location. 


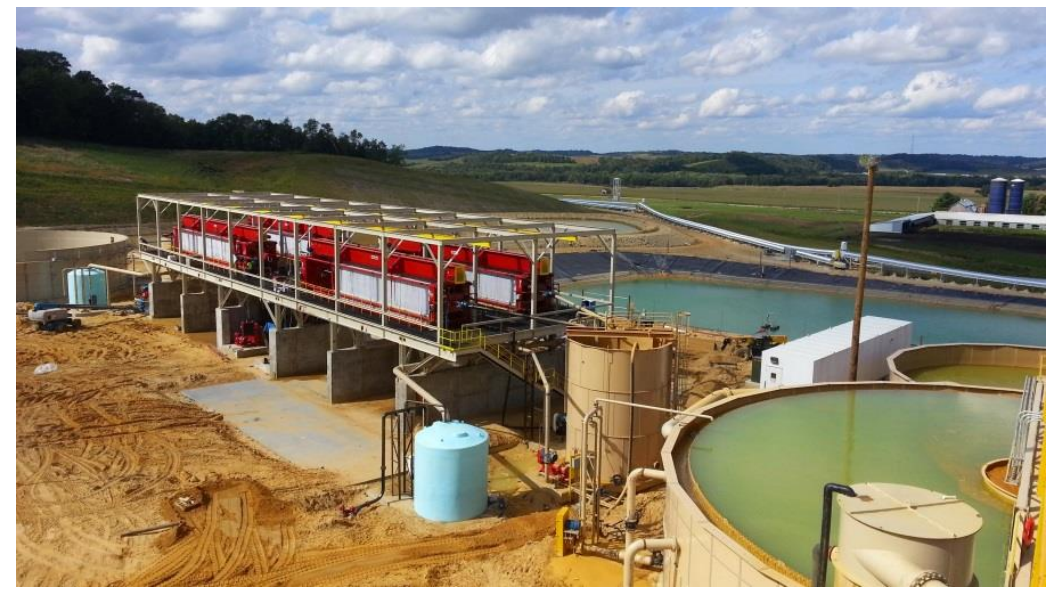

Figure 4 Recessed plate presses are a familiar tailings solution for frac sand producers

\subsection{Site C, Indiana, USA}

The mine in Indiana, USA which operated a high rate thickener for refuse was running out of space for in their current refuse ponds. In order to reach compaction they wanted to get a dry enough cake that when mixed with their coarse refuse would allow them to meet compaction requirements and eliminate the need for future settling ponds.

After testing and working with multiple vendors the customer decided that using either recessed or membrane plate filter presses were the best option in order to meet their compaction requirements. Pilot testing was performed on site to generate enough filter cake to ensure the moisture levels reached would perform adequately to meet their compaction requirements for their reclamation plan. In the end, they decided to install:

- 2 each $\times 180$ Plate $2 \mathrm{~m} \times 2 \mathrm{~m} \times 25 \mathrm{~mm}$ Recessed Chamber.

- 2 each $\times 151$ Plate $2 \mathrm{~m} \times 2 \mathrm{~m} \times 40 \mathrm{~mm}$ Membrane Plate.

Note that all four filter presses, shared a common size filter press frame, and all fed from a common single agitated surge tank.

Because the Membrane plate presses were able to achieve slightly lower moisture contents in testing (2 3 points drier) it was decided by the customer to install 2 recessed chamber presses which have lower operating costs and 2 membrane plate presses which achieved slightly lower moisture cakes. This would allow the customer to blend the cakes as needed to achieve the compaction requirements.

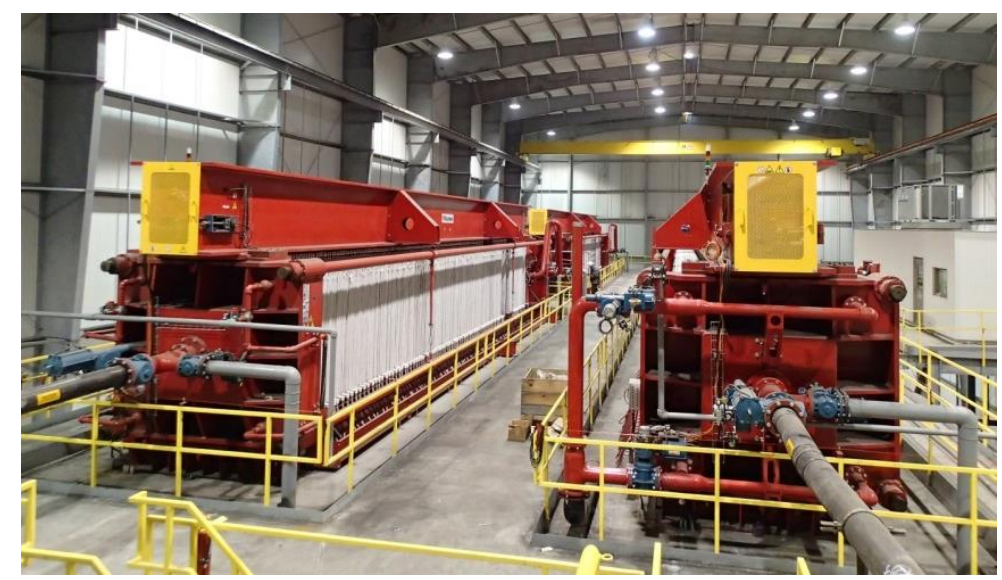

Figure 5 Inside the Indiana filtered coal refuse facility 
The recessed chamber filter presses operate with total cycle times of $20 \sim 24 \mathrm{~min}$, at 15 Bar pressure, with the cycle including the $3 \mathrm{~min}$ of cake blow. The resulting filter cake has an average cake solids content of 77 78\% by mass.

The $40 \mathrm{~mm}$ membrane plate filter presses operate with a feeding pressure of 8 Bar and squeeze pressure of 15 Bar with a total cycle times $20 \sim 24$ min including 3 min of cake blow. The resulting filter cake has an average cake solids content of $78^{\sim 79 \%}$ by mass.

\subsection{Site D, Victoria, Australia}

This site had an existing tailings handling facility consisting of a high rate thickener and several belt press filters. Depending on availability of the belt press filters either a sludge or wet tailings was sent to the Tailings Storage Facility (TSF). There was need to replace the TSF due to operational constraints and permission to either extend or build a new TSF was deemed unlikely to be approved by the regulating authorities, and so an alternative solution was required.

After test work a single $2 \times 2 \mathrm{~m} 180$ plate filter press was selected for $35 \mathrm{t} / \mathrm{hr}$ with a cake moisture of less than $28 \%$ by mass. The filter press is fully automatic running on a cycle time of 35 minutes. Again this was located over a concrete bunker with the cake solids being mucked out approximately two times per day by front end loader. This is then trucked to the disposal area. The fine particle distribution limited the cake thickness to $25 \mathrm{~mm}$ but by selecting a thin cake the filter was able to produce the required moisture without need for operationally intensive membrane squeeze nor any cake blow.

The commissioning process highlighted the connectivity of the thickener operation to filter capacity and optimization of the thickener operation was also provided by the vendor.

Like Site $A$ this operation has been able to recover additional cost by finding a market for the fine clay tailings in a construction application, which in turn as the additional benefit of a reduced disposal site footprint
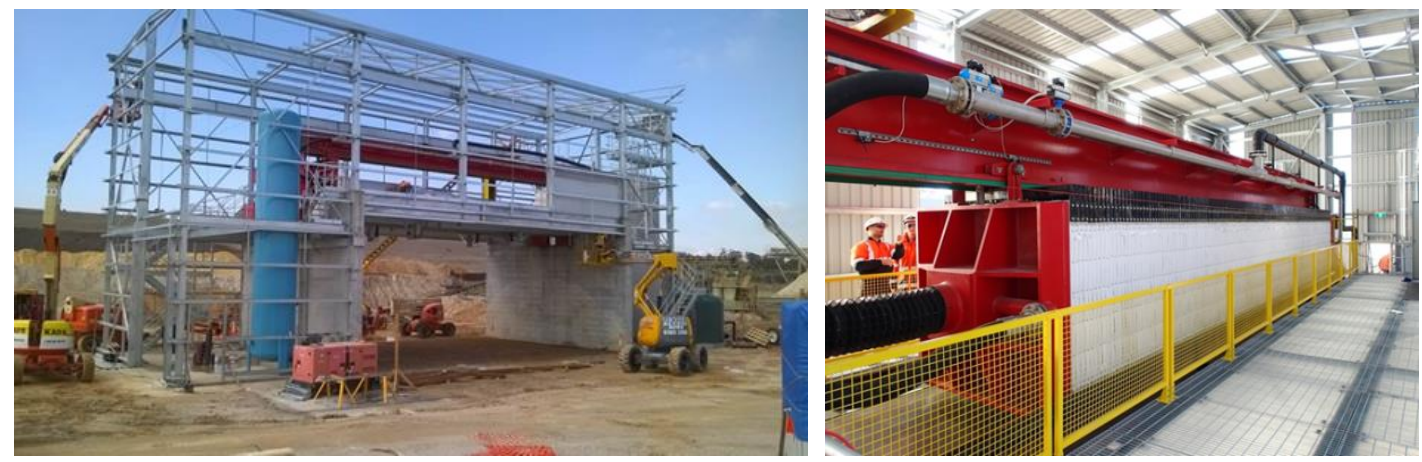

Figure 6 Overhead beam press being installed and commissioned in Victoria aggregates facility

\section{Conclusions}

Several examples have been presented for small scale economic filtered tailing applications. Common features around the justification of these plants are included: legislation over tailings deposition, costs of managing tailings storage facilities, recovery of area for additional production use and the ability to gain some value for the previously valueless material.

Optimal outcomes for each site are equally dependent on local socio-economic environment as well and the specific process details. Selecting partners with experience in both facets are critical to achieving the best value for each project. 


\section{References}

Arash, R., Seddon, K. and Pavissich, C.I. 2016, 'Optimization of tailings management schemes: comparison of tailings filtration and paste', in S. Barrera and R.J. Jewell (eds), Proceedings of the 19th International Seminar on Paste and Thickened Tailings, Gecamin, Santiago, pp. 170-180.

Fawell, P.D., Farrow, J.B., Heath, A.R., Nguyen, T.V., Owen, A.T., Paterson, D., Rudman, M., Scales, P.J., Simic, K., Stephens, D.W., Swift, J.D., and Usher, S.P. 2009, '20 years of AMIRA P266 "Improving Thickener Technology" - how has it changed the understanding of thickener performance?', in R.J. Jewell, A.B. Fourie, S. Barrera and J. Wiertz (eds), Proceedings of the 12th International Seminar on Paste and Thickened Tailings, Australian Centre for Geomechanics, Perth, pp. 59-68.

Kynch, G.J. 1952, 'A theory of sedimentation', Transactions of the Faraday Society, vol. 48, pp. 166-176.

Van Zyl, D., Shields, D., Agioutantis, Z. and Joyce, S. 2017, 'Waste not, want not - rethinking the tailings and mine waste issue', AusIMM Bulletin, pp. 38-42.

Voss, R., 2013 Personal Communication. 